\section{LA HISTORIETA ESPAÑOLA EN EUROPA Y EN EL MUNDO}

\author{
Viviane Alary \\ Universidad Blaise Pascal, Clermont-Ferrand
}

\begin{abstract}
It is intended to show a serious thought on the Spanish comic produced abroad or made for foreign countries. The study follow different trails, examining three generational groups, studying relevant signatures covering all phenomenon related to the comic industry and those linked to the Art and the experimentation. This article focusses on the historical period from the Spanish civil postwar to the present time because from the 1940 decade there has been a much wide scope movement. The proposed reflection is about the exile (political, existential or labor one, or even physical or artistic) when the work is done in Spain and sent abroad. Different periods are analized as, by the time, the exile was massive or more discret and meant a penetration more or less asserted in British, French or Belgian markets. Our aim is giving a value to each generation and give each one its own international appreciation, in both collective or individual ways. This article specially focusses in the cumulating experience, the transferences in the European way of doing and the American way through the Spanish school; we are trying to give a first answer to Spanish school invisibility problem, existing nearly until the present time. Finally, we are showing the Spanish contribution to the current creation in the comic world, and talking about its recently obtained legitimacy.
\end{abstract}

KEY WORDS: Spanish comic; international wide scope; exile; agency market; current creations.

Si queremos abordar la historieta española planteándonos cuál es el sitio que le corresponde en el ámbito internacional y cuál es su aportación al patrimonio mundial de la historieta, no podemos sino convocar el perspectivismo orteguiano: según se mire el objeto, tendremos aproximaciones diferentes y relatos diferentes. Por lo tanto, seguiré en este estudio varios hilos que van desde el examen de tres grupos generacionales hasta el estudio de unas firmas relevantes, abarcando tanto los fenómenos ligados a la industria del cómic como los que le vinculan al arte y a la experimentación. Me centraré en el periodo histórico que va de la posguerra a la actualidad, pues solo a partir de los años cuarenta se inicia un movimiento de mayor proyección hacia fuera. Un retrato de la historieta española en el ámbito internacional no se puede valorar sin tomar en cuenta los enriquecedores intercambios, transferencias de modelos, estéticas, tendencias,

\section{THE SPANISH CARTOON THROUGHOUT EUROPE AND THE WORLD}

RESUMEN: Se pretende ofrecer una reflexión sobre el cómic español producido fuera de España o para el extranjero. El estudio sigue varias pistas, que van del examen de tres grupos generacionales al estudio de unas firmas relevantes, abarcando tanto los fenómenos ligados a la industria del cómic como los que se vinculan al arte y la experimentación. El artículo se centra en el periodo histórico que va de la posguerra civil a la actualidad, pues, es a partir de los años cuarenta cuando se inicia un movimiento de mayor amplitud de proyección hacia fuera. La reflexión propuesta versa sobre el exilio, sea político, existencial 0 laboral, físico o artístico, cuando se trabaja desde España para el extranjero. Se analizan diferentes periodos durante los cuales este exilio fue masivo o más discreto y supuso una penetración más 0 menos afirmada de los mercados anglosajón o francobelga, con el objetivo de valorar la aportación de cada generación y su reconocimiento internacional, colectivo 0 individual. El artículo hace hincapié en la experiencia acumulada, los transvases entre modo de hacer europeo y americano por medio de la escuela española e intenta dar una primera respuesta al problema de la invisibilidad de la escuela española hasta hace poco en el tablero internacional. Termina demostrando la aportación española a la creación contemporánea en historieta y la reciente legitimidad adquirida.

PALABRAS CLAVE: Historieta española; proyección internacional; exilio; mercado agencial; creación contemporánea.

experiencias, prácticas entre España y el resto del mundo. Así pues, la perspectiva intercultural ayudará a entender la relación entre la historieta española, europea y mundial.

\section{DESTINOS Y OBRA DE LOS HISTORIETISTAS AFECTADOS POR LA GUERRA CIVIL}

Los contactos e intercambios entre España, Europa o América Latina fueron siempre fructíferos. Muchos dibujantes y pintores, entre los cuales destacadas figuras de la historieta española, como Salvador Bartolozzi u Opisso, a principios del siglo XX emprendieron viajes artísticos por Francia, Italia o Alemania. Algunos colaboraron con revistas europeas. Otros emigraron. Tal es el caso, de Regino Bernad, 
que se instala en Francia en 1924 y dibujó durante 15 años, en los años cincuenta y sesenta, la serie de gran éxito popular Chéri-Bibil para el periódico France-Soir. Pero nada tienen que ver esos movimientos migratorios con lo que aconteció después de la guerra civil.

Dentro del país, como señala Antonio Martín en sus estudios sobre la guerra civil, al finalizar la contienda, muchos encontraron un refugio en la historieta. Aunque queda por determinar exactamente la amplitud del fenómeno, es cierto que la historieta se benefició de este exilio interior. A esa realidad, conviene añadir otra. La industria del tebeo se recuperó pero en unos momentos en que prevalecía una autarquía económica y política. Lo hispánico debía prevalecer hasta en la contratación de colaboradores. Ambos factores se aunaron haciendo que se constituyera un verdadero semillero en España y que se intensificara un movimiento hacia el extranjero. El reconocimiento internacional no tardó en manifestarse en el caso de uno de los más grandes historietistas españoles, Emilio Freixas (1889-1976), a quien la National Cartoonist Society de Nueva York le otorgó ya en 1947 el premio al mejor dibujante.

Al igual que existe una literatura del exilio, existe también una historieta del exilio como consecuencia de la guerra civil y de la dictadura. No obstante, es difícil distinguir lo que participa de un exilio político de lo que es simplemente emigración laboral. Por razones ideológicas, económicas o simplemente existenciales, grandes nombres de la historieta se fueron de España, exiliados o simples emigrantes no podían aguantar el aire viciado de la posguerra o la falta de perspectivas en un país estancado. Las tierras de acogida fueron: México, Chile, Estados Unidos, Venezuela, Francia, Argentina, Reino Unido; los soportes: la prensa cotidiana, revistas, editoriales franco- belgas, mercado agencial europeo 0 americano.

Para algunos, el exilio fue definitivo, muy a pesar suyo, y dramático en el caso de Salvador Bartolozzi. Para otros, fue un intervalo más o menos largo, como para Ambrós (19131992), cuya estancia en Francia -unos cuatro años- no puede considerarse decisiva en su carrera. Al contrario de Carlos Freixas (1923-2003), cuyo episodio argentino (19471956) supuso una verdadera inflexión estilística al formar parte de ese grupo mítico de la Escuela Panamericana de Arte junto a José Luis Salinas, Héctor Oesterheld o Hugo Pratt.

\section{DIÁSPORA}

Reconocidos como claros exponentes de un periodo de la historieta española, aunque escogieron marcharse y a veces volver para marcharse otra vez, recalcaré las diferentes caras de la proyección internacional de autores afectados por la guerra civil y la dictadura cuya obra se extendió de los años cuarenta hasta la actualidad en ciertos casos.

Después de una intensa colaboración en las revistas dirigidas por Consuelo Gil, el fracaso del intento de crear una editorial (M osquito), ante un futuro profesional incierto y en un difícil contexto de posguerra (El ladrón de pesadillas y otras historias, 2006: 6), Ángel Puigmiquel permaneció en Venezuela durante doce años donde colaboró con otros españoles (Alfons Figueras, Arturo Moreno y Joaquín de Haro) en revistas y dibujos animados. Es una de las figuras que gozó de reconocimiento internacional, aunque el sueño americano lo alejara de la historieta. En este caso no podemos sino preguntarnos, vista la singularidad de su obra, ¿qué habría sido de este artista sin la etapa venezolana?

José Cabrero Arnal (1909-1982) ya tenía una importante producción en España (empezó en $T B O$, luego colaboró en KKO, pero fue en Pocholo - donde creó su perro Top-y en Mickey donde alcanzó la fama) cuando tuvo que exiliarse en 1939. Se convirtió en uno de los creadores de la bande dessinée de posguerra que más popularidad ha tenido en Francia donde conoció la deportación, los campos de concentración franceses (Argelès, Saint-Cyprien, Agde) y alemanes (Mathausen). Después de diez años de horror y miseria, reanudó con la historieta animalizada creando en 1946 Placid y Muzo para la revista Vaillant y luego Pif le chien, que aparece por primera vez en el periódico L'Humanité el 3 de marzo de 1948. El personaje pasará luego a Vaillant antes de convertirse en mascota de la famosa revista Pif Gadget² (imagen 1).

Huyendo del franquismo y de una industria que no dejaba espacio para nuevos contenidos, la marcha a Francia de Julio Ribera o de Antonio Parras es representativa de un exilio tanto político como laboral.

Julio Ribera (1927) emigra a Francia en 1954. Después de realizar unos trabajos para la prensa, colabora en Vaillant, Pilote (Dracurella, 1973), realizando varias series de ciencia ficción hasta la mítica Le vagabond des Limbes, patrimonio 


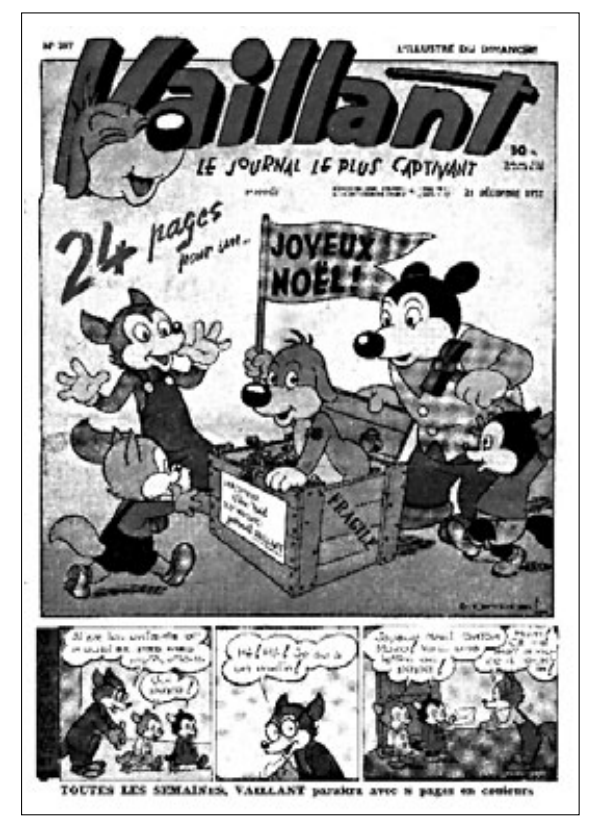

Imagen 1. José Cabrero Arnal, primera aparición de Pif le Chien en la revista Vaillant, portada del n 397 (21 de diciembre de1952, archivo Période Rouge).

de la bande dessinée francesa. Entre 2004 y 2006 publicó una trilogía, Montserrat (ed. Bamboo), donde cuenta sus recuerdos de la guerra civil y su juventud bajo el franquis$\mathrm{mo}^{3}$. Esta recuperación de la memoria personal o colectiva por parte de los exiliados ${ }^{4}$, entronca con una extensa e intensa producción dentro de España.

Antonio Parras (1929-2010) se instaló en Francia en 1955. Como muchos españoles, colaboró en las revistas infantiles del momento (Spirou, en las famosas "Histoires de I'Oncle Paul", Le journal de Tintin) antes de pasar al cómic más adulto en Pilote. Dibujante discreto, se dio a conocer a un público más amplio en Francia gracias a Les inoxydables, sobre guión de Víctor Mora, prepublicado en Charlie Mensuel y después en álbum (Dargaud, 1984), a continuación con las series Le Lièvre de Mars (siete tomos a partir de 1993) con el guionista Patrick Cothias, y Le Méridien des Brumes con Erik Juszezak (dos tomos) en Dargaud.

A Julio Ribera y Antonio Parras se les reconoce como españoles, pero sus carreras se desarrollaron en el ámbito franco-belga, en un momento de gran florecimiento de revistas y colecciones que se dirigían cada vez más a un lector adulto.
Participaron en esa aventura editorial y contribuyeron a dar sus letras de nobleza a la bande dessinée a través de sus colaboraciones en las revistas y editoriales más prestigiosas.

Gilles Ratier en un artículo homenaje a Víctor de la Fuente (1927), que también falleció hace poco en Francia (julio de 2010), donde residía desde 1975, presenta a este dibujante como "uno de los más grandes artistas realistas españoles del siglo XX" (portal Bdzoom, de 6 de julio de 2010). Su trayectoria personal es muy representativa de dos momentos de proyección internacional de los autores españoles (los años cincuenta-setenta). Durante la posguerra su marcha a América parece más una emigración laboral. Se desenvuelve entre Chile y Estados Unidos mientras sigue colaborando con revistas españolas (Maravillas, Chicos). Regresa a España en 1959 para emprender una nueva carrera antes de partir, defraudado, hacia Francia en busca de un mercado más acogedor. Este segundo exilio puede ser entendido como artístico. La trayectoria de este gran dibujante, las idas y vueltas a España, implican inflexiones en su carrera. Introdujo los temas de Heroic fantasy en Europa e influyó mucho en las generaciones de jóvenes dibujantes (Gilles Ratier, Bdzoom, 6 de julio de 2010). Autor prolífico y consagrado 5 con títulos memorables como Sunday, Haxtur, Mathaï-Dor, editados por Hachette y Dargaud en los años setenta, su asentamiento en el ámbito franco-belga se traduce en una colaboración con los más prestigiosos guionistas del momento (J ean-Michel Charlier, Guy Vidal, Víctor M ora, Patrick Cothias....). No deja de ser paradójico y al mismo tiempo significativo que lo que se considera su obra maestra Haggarth -que los franceses descubrieron en el $n^{\circ} 4$ de la mítica revista (À Suivre) en 1978- no fue nunca publicada en álbum. Por su historia personal y profesional, por su vuelta al mundo del cómic - como profesional que trabaja para agencias o como autor- es el más internacional de la escuela realista ibérica. Los reveses que sufrió -censura en España, dificultad para convertir en álbum lo prepublicado y encontrar sus lectores- resulta sintomático de los problemas que, aunque reconocidos, tendrán los autores españoles para publicar y defender sus derechos dentro o fuera de España.

\section{LOS QUE SE QUEDARON}

Entre los que se quedaron, Jesús Blasco (1919-1995) es el de mayor reconocimiento tanto nacional como internacional6. Creador del más famoso personaje del tebeo español, 
Cuto, colaboró con la ayuda de sus hermanos, Adriano y Alejandro, en las series o revistas más emblemáticas de Inglaterra, incluido el semanario Valiant. A principios de los años sesenta empezó a realizar una de las más populares series británicas, The steel Claw (imagen 2), que marcó a toda una generación de dibujantes. Asimismo, dejó una extensa obra en Francia (Les Guerilleros, con guión del español Miguel Cussó), en Spirou (1968-1970) y en la serie Paul Foran sobre guión de otro español, José Ramón Larraz, también dibujante colaborador de Spirou. Prolífico y defensor de sus derechos de autor desde su estudio-taller que compartía con sus hermanos, realizó gran número de historietas para revistas juveniles inglesas, alemanas, italianas, danesas, finlandesas, belgas... y también algunas historias para Warren y Marvel Comics.

Antonio Hernández Palacios $(1921,2000) 7$, maestro renovador del género histórico, es reconocido en el ámbito internacional a través de publicaciones como los tres álbumes sobre la guerra civil, Eloy, Río Manzanares y 1936, en Les Humanoïdes Associés (1981-1982), relatos inaugurales de una larga serie que autores españoles y europeos dedicaron a la contienda en España. Su carrera de historietista se inició en Chicos en 1943. Trabajó para las agencias españolas Histograf e Ibergraf. Trataba tema histórico, aventuras, género del Oeste. Al igual que Víctor de la Fuente, empezó

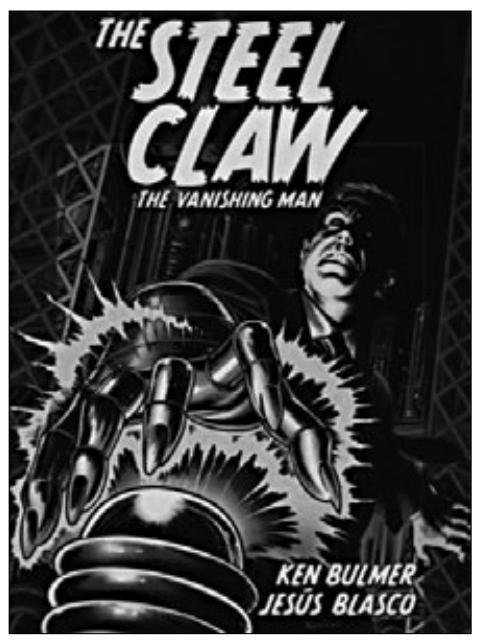

Imagen 2. Jesús Blasco, Ken Bulmer, portada de la reedición en formato "graphic novel", The steel Claw, The vanisching man, Titan Books, 2006. una carrera de autor de cómic desde la revista Trinca, que le permitió alcanzar las editoriales franco-belgas donde se impuso en el género del Oeste con planteamientos adultos, con títulos inolvidables como Manos Kelly, Mac Coy, o L'or des caballeros y en el género histórico (Roland à Roncevaux, Le Cid) donde su estilo adquirió rigor descriptivo matizado por una gravedad épica sublimadota, aunque grandilocuente 0 demasiado austera para algunos. Tuvo buena acogida en Francia, pues las composiciones de este gran ambientador de espacios, pintor e ilustrador de carteles de cine ${ }^{8}$, se encontraron a sus anchas en el formato álbum.

\section{Mercado agencial}

El trabajo agencial para el extranjero fue y sigue siendo, puesto que sobrevivió al franquismo, un fenómeno de gran magnitud. Agencias españolas: Histograf, Bardon Art, Ibergraf, Creaciones Editoriales, Selecciones Ilustradas y más tarde Norma 0 agentes como José Gallardo o dibujantes trabajando por libre 0 en familia (los Blasco) se dieron cuenta del interés de trabajar para el mercado extranjero. $\mathrm{Si}$ nos adentramos en este mundo de las agencias, nos encontramos con un sinfín de firmas españolas. Algunos con una intensa actividad en el tebeo nacional, como el ya citado Jesús Blasco o Francisco Hidalgo o Francisco Blanes... otros, más o menos reconocidos, incluso anónimos, se pusieron al servicio de una industria extranjera, francesa, anglosajona 0 , más tarde, americana para encontrar una salida laboral. La aventura agencial dejó grandes nombres, pero detrás de estos nombres reconocidos al nivel internacional, multitud de buenos dibujantes pasaron desapercibidos. Destajista de la industria, el historietista no tenía la posibilidad de controlar y hacer respetar sus derechos de autor.

Según uno se interesara por el género de terror o del Oeste, fuera lector asiduo de Spirou o Valentine, ciudadano americano, argentino, francés o inglés, o leyera la producción de petits formats en Francia en los años cincuentasetenta, 0 el cómic de género y de superhéroes americanos, o tuviera algún interés por la producción sentimental difundida por editoriales británicas, no pudo sino apreciar el profesionalismo y la inventiva gráfica de los dibujantes españoles. Fue un fenómeno masivo. Procediendo de escuelas diferentes, madrileña, valenciana, catalana, los 
españoles constituyeron una cantera de profesionales para la industria europea y americana.

Entre la generación de mitad de siglo, algunos de ellos profesionales muy conocidos en España, muchos se exiliaron. Francesc Batet Pellejero dejó Barcelona para instalarse en París en 1952 donde colaboró con France Dimanche y Hachette. José Laffond y Díaz-Albo (1926-1971) eligió instalarse en Francia en 1956 donde realizó varias "Belles Histoires de I'Oncle Paul" para Spirou con su hermano Carlos antes de desarrollar una intensa y prolífica actividad con la agencia Opera Mundi que colocó sus trabajos en los grandes periódicos franceses de aquel entonces (Le Parisien Libéré, L'Aurore, L'Humanité). La contribución de dibujantes hispánicos a la prensa franco-belga es considerable y pasar lista sería siempre incompleto. Migraron de una revista a otra utilizando seudónimos, como Francisco Hidalgo -Yves Roy para Pilote- 0 Juan Arranz -Jeandedieu para las ediciones Fleurus-, José Laffond - 0 Barque en sus adaptaciones de Julio Verne-, Jorge Domenech -Jor. Dom, en la prensa católica-, Luis García-Gallo -que firmaba sus dibujos $\operatorname{Coq}^{9}-\ldots$ y resulta difícil seguirles la pista.

La implicación de los españoles en el mercado franco-belga empezó temprano en revistas infantiles y en la prensa, más tarde en revistas de historieta destinadas a adultos (Pilote, A suivre, Circus, Charlie Mensuel, Metal Hurlant I'Echo des Savanes, etc.). Dejaron su impronta en obras más didácticas como la ilustración de la Biblia (Víctor de la Fuente, José Bielsa, Larousse, 1983) o la famosa Histoire de France en bandes dessinées en 24 álbumes (Vosé Bielsa, Víctor Mora, Víctor de la Fuente, Julio Ribera, Enric Sió). Francia empieza a darse cuenta de lo relevante que ha sido la aportación española, rindiendo homenaje a los recién fallecidos Antonio Parras y Víctor de la Fuente y tomando conciencia de que toda una generación española que contribuyó a dar sus letras de nobleza a la edición franco-belga está desapareciendo sin que se haya planteado ni su existencia ni el papel que desempeñaron. Por parte de la investigación científica, historiadores de la cultura popular empiezan a interesarse por el tema como es el caso de Philippe Videlier que trabaja sobre el papel de un grupo de dibujantes españoles, que colaboraron en los famosos petits formats en Lyon, para Imperia (1953-1986, 613 números). Este estudioso cruza el destino de Luis Ramos, Pedro Martínez Henares, Rossend Franch, Adolfo Bullya, José Marí Ortiz, Carlos Laffond, y también, Carlos Giménez que realizó Les Trackers entre 1969 y 1971 algunos episodios de la serie Buck John (Buck Jones).

En la España dictatorial del desarrollo económico, la rigidez del mercado nacional y la falta de perspectivas confirman la atracción por el mercado internacional (Francia, Italia, Inglaterra, Estados Unidos...). Es un momento de intensa actividad profesional con la llegada de una nueva generación que se da cuenta, como es el caso del dibujante José Toutain, fundador de la agencia Selecciones Ilustradas, del interés en mirar hacia fuera. Este movimiento concierne tanto a dibujantes como a guionistas, entintadores, coloristas o ilustradores de portadas y todo tipo de géneros: Oeste, ciencia ficción, historias románticas, género bélico, terror.

En sus Memorias ilustradas (Glénat, 2004), Fernando Fernández cuenta que, a finales de los años cincuenta, empieza para él y sus compañeros una intensa colaboración con las revistas inglesas quinceañeras. $A$ través de las agencias españolas, se difundían historietas románticas de Luis García, Mari Carmen Vila (Marika), Enric Sió, Esteban Maroto... por toda Europa. La Fleetway Publications y sus revistas románticas Mirabelle, Valentine, Marilyn o Roxy tenían su núcleo de dibujantes españoles como J orge Longarón, José María M iralles y J osé González (Pepe) cuyas figuras femeninas se convirtieron en modelo gráfico muy imitado. Quizá uno de los mayores reconocimientos internacionales en este género recae en la serie Patty's World (Esther y su mundo en España) de Purita Campos (1937) con guión de Philip Douglas que a partir de 1971 hasta 1988 fue difundida por toda Europa.

Desde sus comienzos los dibujantes aprenden y se copian explorando gráficamente la figura femenina con soltura y cierta libertad. Este intenso trabajo agencial repercutió en los estilos gráficos que cada historietista irá elaborando con el tiempo en sus obras más personales. Resulta más evidente en el caso de Luis García, Fernando Fernández y en Marika. Así pues, la implicación española en este género supuso una primera apertura -tan difícil en España por aquel entonces- hacia un lectorado de jóvenes adultos, hecho que se confirmó con las colaboraciones españolas en otros géneros: Oeste, historieta bélica y sobre todo terror y fantástico.

El género bélico constituyó con el del Oeste la segunda faceta de la proyección internacional de los años sesenta y 
setenta. En el mercado inglés Fleetway produjo series basadas en la aviación o la infantería y solicitó a colaboradores de todos los países entre los cuales destacan numerosos españoles (Luis Bermejo, Fernando Fernández, Víctor de la Fuente, Luis García, Manfred Sommer, J osé Ortiz, Leopoldo Sánchez Ortiz...). Como lo recuerda Fernando Fernández (Memorias llustradas, 296), esos jóvenes se codeaban con ingleses, italianos 0 argentinos de la talla de Breccia o Hugo Pratt ${ }^{10}$. Sin duda la renovación de la estética del blanco y negro heredada de los americanos como Milton Caniff, se ideó en esas producciones agenciales.

A los trabajos para las revistas sentimentales 0 de aventuras le siguió, en los años setenta, la ola de los géneros de terror, ciencia-ficción y fantástico para la industria americana y más en particular para la editorial Warren. Esta experiencia trasatlántica fue también otra excelente escuela del blanco y negro y contribuyó a la difusión internacional del material español. Se recuerda en España este momento como boom de los dibujantes españoles en Norteamérica (Jordi Costa, Cimoc, $\left.n^{\circ} 21,1981\right)$. En su momento, Antonio Martín dedicaba un suplemento de la revista Bang! $\left(n^{\circ} 9,1973\right)$ a resaltar la buena acogida que recibían los autores españoles publicados en Creepy, Eerie o Vampirella y la consecuente y merecida avalancha de premios: en 1971 Esteban Maroto fue "el primer dibujante español que logró triunfar en los Estados Unidos" (Koldo Azpitare, 2006: 22-24) ganando el Foreing Award de la Academy of Comic Book Arts. En 1973 se otorgaron cuatro premios a españoles: Manuel San Julián, Víctor de la Fuente, Luis García y José María Beá. También fueron premiados J osé González (en 1971 y en 1976) contratado para dibujar el personaje de Vampirella (imagen 3) 0 Leopoldo Sánchez Ortiz, dando así un reconocimiento internacional a lo que podríamos calificar de "escuela española Warren" cuyos nombres no podemos enumerar exhaustivamente pero cuentan con firmas como la de J osé Ortiz, Alfonso Font, el guionista Antonio Segura o Luis Bermejo. Como lo afirma Vicente Sorní, esta escuela española Warren "contribuyó al fulgurante éxito de las revistas Warren" (El Tebeo valenciano, de Ponent, 2007: 207).

Desvinculados de España, conviene recordar en este apartado algunos españoles que decidieron marcharse. José Luis García López fue a vivir a Argentina y luego a Estados Unidos. Colaboró en Batman o Tarzan y adquirió reconocimiento internacional por sus colaboraciones para Superman en la

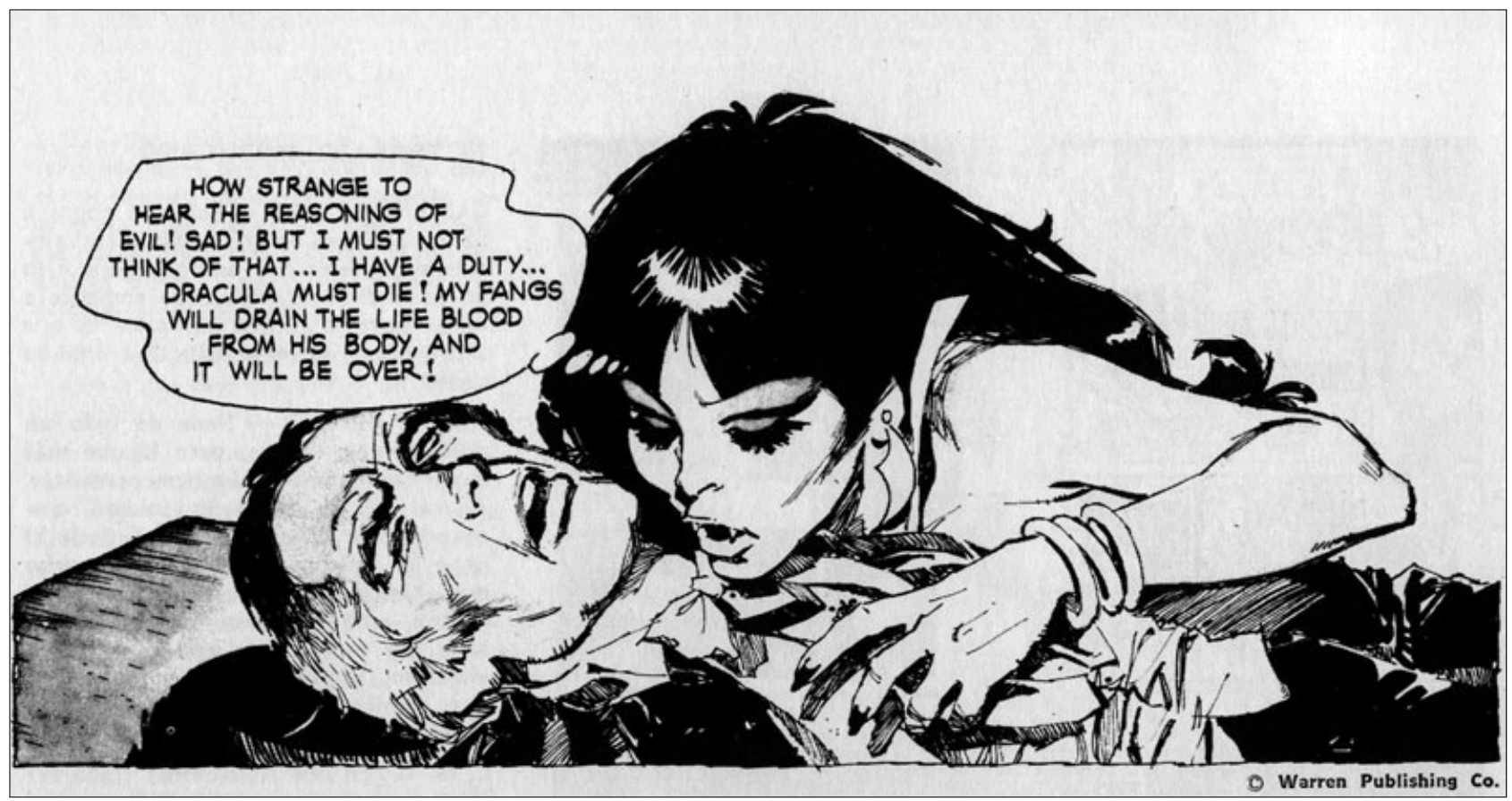

Imagen 3. José González, Vampirella en Bang! nº 9, Martín Editor, 1973. 
segunda mitad de los años setenta. Vicente Alcázar (1944) se estableció en Inglaterra donde sus personajes fueron muy populares en los años sesenta antes de marcharse por Estados Unidos. Carlos Ezquerra (1947), procediendo de la agencia Bardon Art, vivió diez años en Londres, antes de afincarse en Estados Unidos. Trabajó para Fleetways donde creó el famoso Judge Dredd (Juez Dredd).

La aventura agencial fue palpitante y supuso ingresos a corto plazo -los dibujantes sacaban ventaja del sistema de cambio de divisas sobre todo con Estados Unidos- y a veces reconocimiento internacional, pero dejó a más de uno sin porvenir profesional una vez estancado el filón de la exportación. Miguel Fuster, uno de esos dibujantes agenciales, cuenta en Miguel, 15 años en la calle (Glénat, 2010), un verdadero descenso al infierno. En los años sesenta era dibujante de cómics románticos para el norte de Europa. No dio el paso hacia otro tipo de salida profesional y en los años ochenta lo perdió todo hasta encontrarse en la calle consumido por el alcohol.

En España la importación y traducción de cómics norteamericanos (historieta de género, superhéroes, terror y ciencia ficción) representaron un momento de transición hacia un cómic para adultos. En las revistas Vampus-Creepy, Zona 84, Cimoc, o Comic Internacional, se podía leer el material norteamericano en el que destacaba la producción de los españoles que trabajaban para Warren. Dibujantes, guionistas, se forjaron un estilo personal en la experiencia agencial, lo que les abrió las puertas hacia un cómic adulto y una producción de autor autóctona. Fue así como la experiencia agencial, aunque anónima y reacia a relatos singulares, benefició a la historieta española.

Esa efervescencia del cómic español repercutió también en la buena acogida de las propuestas de los autores españoles por parte de las editoriales y revistas franco-belgas (Pilote, A suivre, Charlie Mensuel, I'Echo des Savanes, Circus, Metal Hurlant Pilote, Fluide Glacial). En el género de la ciencia ficción, Le Lombard a principios de los años setenta recuperó la serie Dani Futuro de Carlos Giménez, Les Humanoïdes Associés publicó La Sphère cubique (imagen 4), Histoire de la taverne galactique de Josep María Beá, Campus editó Drácula de Fernando Fernández en 1985... Los lectores de Pilote se acercaban a los autores españoles con cierta expectativa, viendo en ellos autores comprometidos leyendo

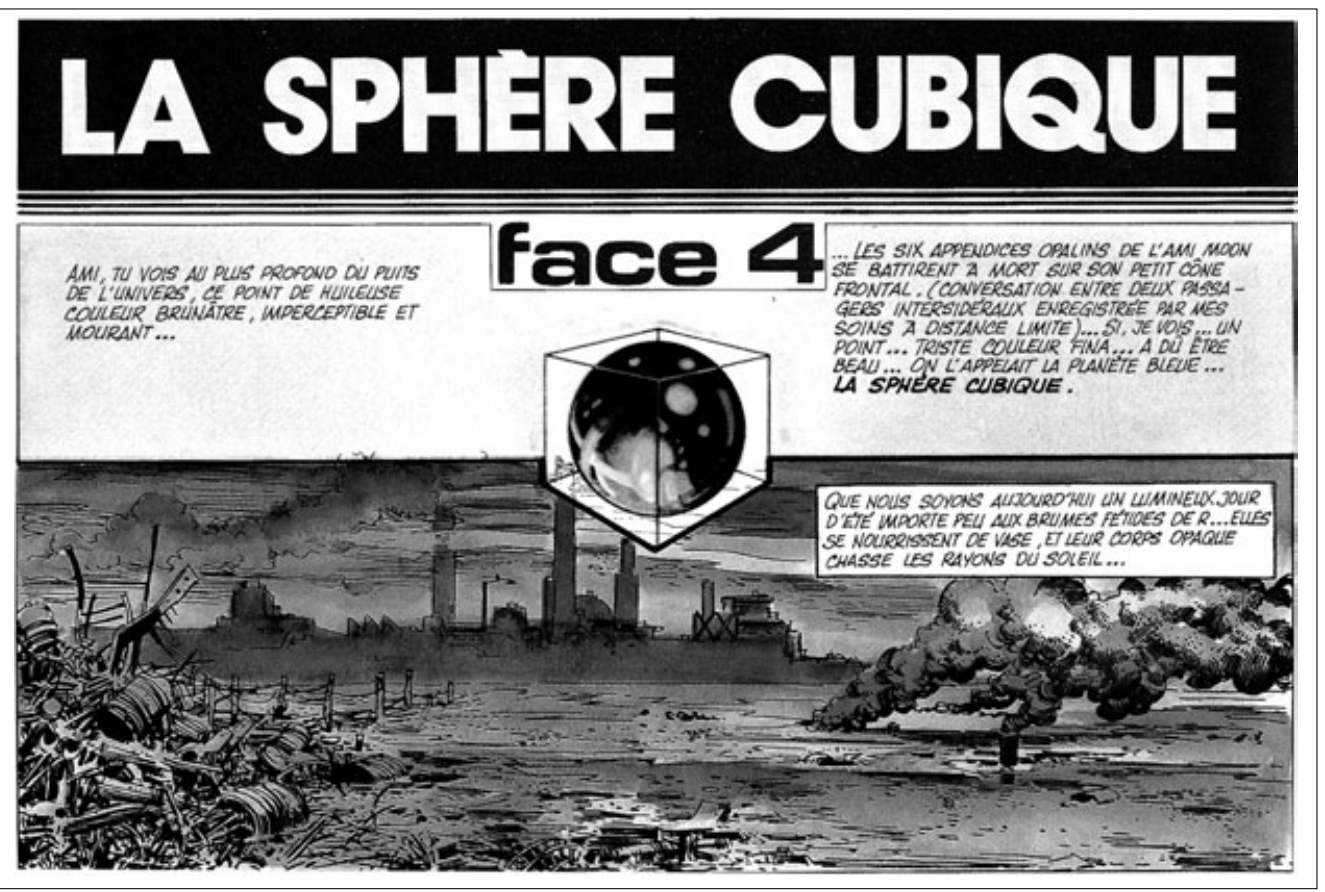

Imagen 4. José María Beá, La Sphère cubique, colección Métal Hurlant, Les Humanoïdes Associés, 1983. 
Les chroniques de l'innommé (Las crónicas del sin nombre), de Luis García con guión de Víctor M ora publicada originalmente en 1973 y difundida luego en Italia y Norteamérica 0 Paracuellos de Carlos Giménez en Fluide Glacial en 1979, verdadera revelación para el lector francés por el contenido tan sobrecogedor y anclado en una realidad vivida por el propio autor. El impacto fue y sigue siendo11 considerable y puede ser comparado a A Contract whith God and other tenements stories de Will Eisner (1978).

Ante las circunstancias laborales y políticas, las opciones fueron muy diversificadas. Enric Sió, que trabajó también para el mercado agencial inglés (historieta sentimental y temas bélicos), reivindicó luego una historieta de arte totalmente desvinculada de su forma popular. Colaborador de Linus donde publicó su obra maestra, Mara en 1971, se exilió a Italia en 1974 y su narrativa fue muy rompedora desde el punto de vista formal.
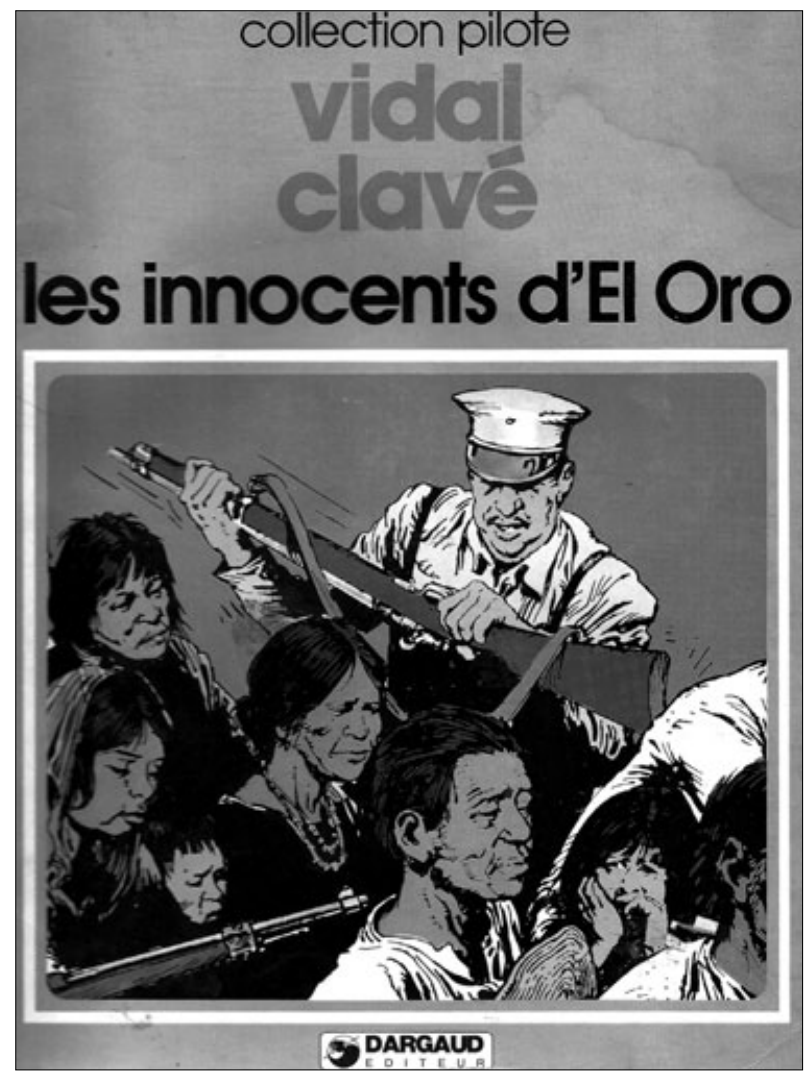

Imagen 5. Florenci Clavé, Les Innocents d'El Oro, colección Pilote, Dargaud, 1977 .
Florenci Clavé (1936- 1998), dibujante español comprometido, colaborador de Selecciones Ilustradas, trabajó para el mercado inglés. Se exilió a Francia a mediados de los años sesenta desarrollando una obra más personal y de autor en Pilote y en revistas europeas (Francia, Italia, Portugal, Suecia, Noruega) o latinoamericanas (Argentina, Cuba). Regresó a España en 1978. Ha dejado una extensa obra en Francia, de la cual solo mencionaremos Les Innocents d'El Oro, 1977, ambientado en el México prerrevolucionario y L'île aux chiens, 1979 (Imagen 5), rápidamente agotado y reeditado bajo el título Sang d'Arménie (1985), que recuerda la tragedia de los armenios, historia que se desarrolla justo antes del genocidio (ambas obras sobre guión de Guy Vidal).

En las antípodas de estas orientaciones, Esteban Maroto, después de publicar trabajos para diversos mercados (inglés, alemán, francés) y en diversos temas (románticos, aventurero o fantástico), siguió otro destino prefiriendo profundizar su colaboración con Warren a raíz del éxito internacional de Cinco por el infinito. Dibujante de muchos recursos y muy talentoso, su implicación en el mercado americano (Warren, Marvel, DC) o italiano (Bonelli) modificó su trayectoria. Evolucionó hacia un clasicismo exigido por la industria y muy del gusto del lector de fantasía erótica y heroica.

Si miramos con lucidez, la aportación de esos autores a la renovación de la historieta es significativa, aunque conviene mitigar este balance al recordar la deserción de autores defraudados que no pudieron vivir de su obra dentro de España ni tampoco confirmar su presencia en editoriales extranjeras refugiándose a finales de los ochenta, en la pintura, la ilustración, o la publicidad aunque algunos realizaron historietas de vez en cuando.

\section{LA NUEVA HISTORIETA Y SU PROYECCIÓN INTERNACIONAL}

Esta aventura transnacional nutrió el caldo de cultivo del boom del cómic adulto que iba a suscitar numerosas vocaciones. Aparecieron propuestas innovadoras en revistas tan diferentes como Madriz, Rambla, Rampa, Cairo, El Vibora, Makoki, El Jueves, Medios Revueltos... Desgraciadamente a las promesas de un futuro abierto, sin trabas editoriales o ideológicas, le siguió un estado de crisis permanente, unas 
políticas editoriales erráticas y un desequilibrio entre las propuestas de los autores y la capacidad receptiva de un público que se apasionaba por la producción americana 0, más tarde, por la japonesa. No obstante, la fragilidad del mercado nacional no supuso un paro brutal de la actividad creadora sino todo lo contrario. Nuevos autores, fanzines, colectivos ofrecieron propuestas estéticas sin parangón en Europa. Eran los años ochenta, acaso los más interesantes desde el punto de vista cualitativo y experimental. Quizá la violencia de la quiebra de la industria del tebeo y la falta de solidez de las estructuras editoriales expliquen las respuestas rompedoras y radicales, contraculturales y estéticas que siguieron y que aportaron mucho a la evolución del noveno arte.

Desde fuera la visión que se tenía del historietista español comprometido dejó paso a otra en apriencia contraria: un autor hedonista que ya no quería hablar del pasado, vuelto hacia el futuro y deseoso de innovación. Aunque en parte falsa -el cuestionamiento estético y estilístico no significó una ausencia de análisis crítico-, es cierto que España fue en los ochenta un laboratorio de experimentos gráficos y narrativos del que se benefició la historieta mundial en diversos grados. ¿Cuáles fueron las principales aportaciones de esa generación que empezó a crear en los años setenta-ochenta?

Los exponentes de esta generación se formaron en fanzines y revistas, creando grupos conectados con colectivos extranjeros. Convendría partir de las posturas de cada autor frente a un panorama muy alentador desde el punto de vista creativo pero deprimente si consideramos las posibilidades de ganarse la vida. Me limitaré a distinguir tres categorías para valorar la aportación española a la creación contemporánea en historieta. Algunos autores encontraron una vía económicamente viable en el extranjero, intentando hacerse un nombre en el mercado agencial. Otros autores navegaron entre encargos, creaciones propias, trabajos para editoriales franco-belgas y mercado americano. Y un tercer grupo privilegió el experimento, el transestetismo o nomadismo estético, los circuitos alternativos e independientes...

\section{UN MERCADO AGENCIAL QUE NO CESA}

Lectores que en su infancia leyeron los comic-book americanos soñaron con hacerse dibujantes de superhéroe y trabajar para las míticas editoriales Marvel o DC. Apasionados y aficionados como Rafa Fronteriz (1961) o Carlos Pacheco (1962) empezaron colaborando con Forum de Planeta DeAgostini, sello español de Marvel, y a finales de los noventa, se incorporaron a la línea Laberinto de dicha editorial, siendo sendas colecciones dirigidas par Antonio Martín. Estos sellos fueron un trampolín para alcanzar el mercado americano, base y escaparate para su proyección internacional.

En 2006 Koldo Azpitarte en un libro de entrevistas dedicado a dibujantes implicados en la industria norteamericana, registró unos 30 autores españoles (dibujantes, entintadores y coloristas) que trabajan de manera regular, a los que habría que añadir colaboraciones de Esteban Maroto u Oscar Jiménez. Muchos pasaron por el mercado británico (Marvel UK), otro trampolín para acceder al mercado norteamericano de superhéroes. Facilitaron los tratos los nuevos modos de comunicación vía Internet y los recursos infográficos. Sería interesante ver cuáles fueron las motivaciones de los historietistas españoles y hasta qué punto hubo transvase de un modo de hacer europeo a un universo que tiene sus propios códigos y que no se deja contaminar fácilmente.

Algunos, como Salvador Larroca, conocido por su rapidez de ejecución, afirma "estoy cómodo en el cómic americano", aunque confiesa que instila una experiencia europea "trato de reproducir detalles (aunque a veces no sean muy reconocibles) que vienen del cómic europeo. Por ejemplo, yo no introduzco prácticamente ninguna línea cinética en mi dibujo y en su lugar suelo meter tantos fondos que muchas veces se me ha acusado de sobrecargar el dibujo" (Azpitarte, 2006: 151).

Carlos Pacheco (1962), el más internacional y reconocido en Estados Unidos en el género de superhéroes (en DC, Marvel Comics Group) colaboró como muchos españoles en series como Fantastic Four, 0 X-men 0 en la inmarcesible Superman. Afirma que, después de tantos años en este mercado, lo importante es sobrevivir, no hacer obra de arte (Azpitarte, 2006: 126-132). Completamente inmerso en la cultura norteamericana de superhéroe y a pesar de su total entrega a la labor agencial, su cultura hispana aflora debido a que, con los años y el reconocimiento, la industria le deja más libertad creativa como en las series Inhumanos o Arrowsmith.

En Pascual Ferry, nacido en 1961, que se inició en el fanzine Zero en los años ochenta al lado de Beroy, Prado, Castells, Garcés, Das Pastoras..., la tensión entre dos mundos 
editoriales se hace más apremiante y se agudiza el eterno dilema artesano-artista. Su irrupción en el mundo de los superhéroes es más circunstancial que la de Pacheco. Lector en la infancia tanto de Astérix, Spirou como de los tebeos Marvel, "hijo del Marsipulami y de Spiderman" confiesa (Azpitarte, 2006: 199-259), la falta de perspectivas en España y la ausencia de un éxito comercial satisfactorio en Francia, le empujó a elegir la carrera de dibujante de agencia. En la entrevista de Koldo Azpitarte se define como "narrador de historias" (Azpitarte, 2006: 203). "A la larga, lo ideal sería poder fusionar mi labor profesional actual con esa necesidad de contar mis propias historias" (Azpitarte, 2006: 204). Todo está dicho puesto que, visto el ritmo de trabajo que pide la industria de superhéroes, parece imposible llevar en paralelo dos carreras.

Ahora, como en los años cincuenta y setenta, el mercado nacional no logra ofrecer un espacio suficiente para que se retribuya de modo satisfactorio la creatividad en este sector. Cuestiones de supervivencia obligan a exportarse y optar por ser artesano 0 artista. Tal y como se pudo constatar en Francia, en la actualidad, España toma conciencia de la necesidad de dar cuenta y analizar este fenómeno de emigración, exilio físico o simplemente artístico tan afirmado desde los años cuarenta. En un espíritu de recuperación del patrimonio nacional, Jesús Cuadrado señala en su diccionario el material extranjero que está todavía por recuperar. Fernando Fernández en sus Memorias ilustradas (Glena, 2004) o Carlos Giménez en Los Profesionales (ed. de la Torre, 1983-1985) dieron testimonio de sus propias experiencias. Existen ahora estudios documentados sobre la magnitud del fenómeno y de su penetración en el mercado anglosajón. Sin embargo, escasean los estudios sobre la presencia de los autores y de la historieta española en el universo editorial franco-belga.

La crítica especializada se interesa más por el manga, de gran aceptación en España por parte del joven público. Y es que una cultura manga está arraigando en el país como hace cuarenta años arraigó la del cómic de superhéroes. Existen ahora colectivos y dibujantes autóctonos y influidos por el manga que interesan fuera: la editorial francesa Akileos edita desde ya hace tiempo el manga español Dragon Fall de Nacho Fernández y Álvaro López; MigueIanxo Prado fue uno de los escasos autores europeos en publicar en Japón (ed. Kodansha). A pesar de todo, la industria nipona del manga sigue siendo un coto vetado a los españoles y a los europeos en general.

\section{LA HISTORIETA DE AUTOR}

En el mundo de las editoriales convencionales que acogieron a autores tan dispares como Vicente Segrelles, Das Pastoras, Ana Miralles, José María Beroy o Pascual Ferry, dos firmas me parecen representativas de la escuela española de los años ochenta y de su aportación a la historieta internacional de autor.

Daniel Torres (1958), cuyas series tuvieron un importante éxito tanto en España y en Francia como en Estados Unidos. Procedente de la escuela valenciana, su grafismo aparece como una síntesis de la tendencia de la línea clara y del comic-book americano. La nitidez del trazo, una imaginación desbordante aunque controlada por su arte del guión, cierta espectacularidad en las composiciones se combinan con un humor distanciado y un placer lúdico de manipulación de los estereotipos. Colaboró con Alan Moore y Dave Gibbons en The Spirit: The New Adventures, Kitchen (Sink Press, 1998). Publicó en las revistas francesas Metal Hurlant y A suivre y fue editado por Futuropolis y Magic Strip, así como por Les Humanoïdes Associés (serie Opium) o Casterman (serie Roco Vargas entre 1985 y 2006). Aunque faltan datos para valorar su aportación, es cierto que su estilo marcó una generación y Paul Pope, uno de los autores americano más talentoso de los noventa, reconoce, entre otras herencias, su deuda hacia Daniel Torres.

Miguelanxo Prado es uno de los historietistas más importante, reconocido por la calidad y complejidad de sus relatos, por la creación de ambientes y atmósferas particulares, tanto a nivel gráfico, plástico como narrativo. Si a eso añadimos una capacidad para pasar de una técnica y de un género a otro -humor, policíaco, crónica, ficción, relato ilustrado, relato infantil-, tenemos en este prodigioso autor una síntesis de lo que puede aportar la renovación española de los años ochenta que integra en su seno la herencia tebeística y la franco-belga. Premiado en Estados Unidos, Francia, Alemania, España, su arte de narrar con imágenes oscila entre experimentación y clasicismo. La pre-publicación de Trazo de Tiza en Á suivre, y su posterior edición en álbum (Casterman, 1993) (imagen 6) supuso un hito importante en la historia del noveno arte. Este relato fue publicado en álbum en diferentes países europeos y en Estados Unidos, (ganador del Alph-art del mejor álbum extranjero en el Festival de Angulema, 1994), y seduce tanto por su aspecto de novela pictórica como por 


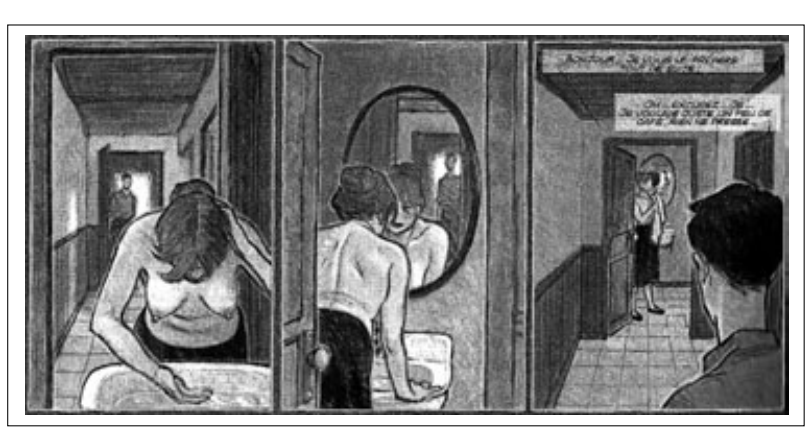

Imagen 6. Miguelanxo Prado, Trait de craie, col. Studio Á Suivre, Casterman, 1993.

un modo de contar basado en un efecto de diz narración y en un sentido literal en suspenso.

Trazo de tiza, como en su tiempo Mara de Enric Sió, demuestran que la historieta española afrontó desde los años setenta el reto de aprender a elaborar una visión compleja de un mundo plural, quitándose ese maniqueísmo y seudo-realismo que parecían consubstanciales. Los autores españoles contribuyeron a que la historieta, tradicionalmente pensada en términos de humor, acción y guiones lineales estandarizados para niños, conquistara nuevos territorios estéticos, lo que finalmente contribuyó a la renovación del álbum infantil como lo demuestran las obras realizadas por Miguel Calatayud, Ana J uan, M ax y M iguelanxo Prado, publicadas ahora en España, Francia y Estados Unidos con gran éxito entre los niños.

\section{LA HISTORIETA ESPAÑOLA EN LA CREACIÓN CONTEMPORÁNEA}

Conviene por lo tanto explicar cómo la historieta española, tan identificada con el realismo, la industria, la serie, la concepción "cinematográfica y canónica" ofrece elementos de ruptura estilística que le permite participar y desempeñar un papel en las tendencias más renovadoras del noveno arte.

Si bien la vía experimental española no pesa nada en términos cuantitativos, representa mucho desde el punto de vista de la legitimación cultural del noveno arte y del cuestionamiento de los estándares. Por eso es imprescindible dedicar la penúltima parte de este vasto recorrido a la aportación española a una nueva historieta alzada a nivel de arte que generó 0 , mejor dicho, reforzó un mercado con sus exposiciones individuales o colectivas de originales en galerías y museos.

Desde los años setenta, se observa una presencia continua de una narrativa gráfica de calidad en España. Aunque desconocida por parte del lector tradicional, la confidencialidad de la difusión no impidió que gozara de fama internacional. La actualidad demuestra que la experimentación llevada a cabo en los años ochenta en España hace de este país un precursor. La "revolución de la forma" en la narrativa gráfica pasa por España que se adelantó a esos movimientos internacionales y participó luego en ellos en torno a editoriales independientes, "bande dessinée d'art et d'essai", historieta alternativa, cuyo apogeo se sitúa más bien en los años 2000. En una entrevista12, Thierry Van Hasselt, de la editorial belga FREON13, declaraba a propósito de su relato Gloria López (2000), que lo que se hacía en España en los años ochenta fue para él una revelación y una fuente de inspiración y citaba Berlín 1931 de Raúl y Felipe Hernández Cava (relatos cortos realizados entre 1985 y 1988 y editados en 1991 en España por Casset Ediciones y Amok en Francia en 1998).

Varios factores propiciaron el dinamismo creativo español. En un momento de derrumbamiento de la industria editorial, los autores optaron por la libertad creativa, la expresión de su mundo interior, las experimentaciones con artes conexas (pintura, ilustración, diseño, novela...). Esta actitud conecta con una realidad sociológica y cultural de la transición democrática. La juventud española más inquieta tenía conciencia de las experiencias escamoteadas y de la importancia de la reconquista de una cultura democrática después de cuarenta años de dictadura. Lo supo poner de relieve internacionalmente la exposición de 1989 en Angulema dedicada a la historieta española14. El nomadismo cultural, característico de las artes en general en los años ochenta en España, fue terreno fértil para que se constituyera una "imaginación nueva" (Calvo Serraller, 1990: 160). La trayectoria de la dibujante Laura es muy representativa de este espíritu de nomadismo cultural. Mediante la historieta nos invita a un viaje por el arte, la filosofía, la literatura, los mitos y el erotismo.

Modo de expresión al alcance de todos, la historieta se convirtió en un símbolo de la cultura democrática renaciente, 
un laboratorio de ideas y experimentos gráficos que luego nutrió los contenidos de artes como el grabado (Ceesepe), el diseño (Mariscal), la pintura (Javier de Juan, Nazario). Revistas y editoriales encauzaron esas nuevas sensibilidades. Aunque de difusión confidencial, Madriz (1984-1987) es la revista que ha gozado de mayor prestigio internacional. Empresa colectiva donde se forjó el talento de autores reconocidos en sectores de la historieta o de la ilustración, Madriz promovió un nuevo modo de crear confrontando la historieta con las demás artes. Sin salir de la asignación al noveno arte, abundaban en ella las experiencias plásticas, narrativas, gráficas límites.

El reconocimiento internacional de esta "nueva historieta" fue progresivo y lento, extendiéndose hasta la actualidad. Laura goza ahora de cierto prestigio. Aunque ausente del mundo editorial francobelga cuyas líneas aún demasiado predefinidas no entroncan con su universo, no para de publicar en revistas de todo el mundo (Suecia, Italia, Argentina, Inglaterra, Portugal, M éxico...) y expone en galerías y centros dedicados a la historieta como Angulema.

Se urdieron en los años ochenta y luego noventa nuevas redes informales entre individuos y colectivos procedentes de España, Europa y América en torno a una historieta deseosa de valorar ante todo la calidad, alternativa a una visión industrial y puramente comercial15. Prueba de esta nueva dinámica, el voluminoso álbum Comix 2000 de 2.000 páginas publicado por la editorial independiente francesa L'Association (2000) que recogió producciones de autores de todo el mundo, entre los cuales se encontraban los españoles Calpurnio, Mauro Entrialgo y Max.

La revista NSLM estableció puentes con Fantagraphics. Artistas españoles trabaron diálogo con revistas confidenciales pero no menos interesantes como Pelure Amère (Federico del Barrio, Felipe Hernández Cava), Le cheval sans tête (M anolo Hidalgo, Federico del Barrio), o Frigo (Raúl). La trayectoria de Federico del Barrio es, en este sentido, bastante reveladora. La aventura tebeística empezó para él en Pilote en 1979. Dejó muy pronto esa vía, demasiado convencional, y adhirió a la línea de Madriz. De ahí conectó con los círculos de la bande dessinée alternativa europea (la revista Pelure Amère, Le Cheval sans tête, la editorial Amok que editó su álbum Relaciones antes de su publicación en España y luego Simple, ambos bajo el seudónimo de Silvestre) y algunas revistas culturales o de arte ("Don Dinero" en la revista Autrement, "Présage" en la revista Beaux Arts) (imagen 7). En la editorial FRM K, se editaron entre 2000 y 2004, sus álbumes Les mémoires d'Amoros con guiones de Felipe Hernández Cava. Es cierto que la presencia de los españoles en esas micro-ediciones franco-belgas siempre fueron aventuras editoriales complejas con ingresos casi nulos. El proyecto de edición de El artefacto perverso (del Barrio, Hernández Cava, Planeta DeAgostini, 1996) en FRM K nunca vio la luz y se tuvo que esperar hasta 2008 para que Les Editions de I'An 2, lo publicara (Le piège, 2008). Aunque esta edición es muy posterior, se presenta en Francia como novedad. Las revistas culturales o de historietas (Telerama, Neuvième art, Bodoï, Les Inrockuptible) hacen hincapié en la novedad de este relato, elogiando su audacia gráfica y narrativa, doce años después de su primera edición.

Podríamos preguntarnos por qué esas obras no fueron reconocidas en su día y por qué el éxito mediático de la nouvelle bande dessinée no alcanzó a la "nueva historieta", muy anterior. Cabe recordar que lo que ahora se admite con naturalidad representaba en su tiempo (años ochenta) una verdadera ruptura que la crítica especializada dominante miraba con recelo. Muchos autores, revistas y hasta editoriales, sufrieron una doble marginación: a la falta de legitimidad cultural de la historieta en general, se le añadía una marginación debida a contenidos juzgados como elitistas, herméticos, no canónicos. Ello impidió una proyección internacional de esos experimentos que, conforme la historieta adquiere legitimidad cultural, se valoran de forma más adecuada. Por otra parte, el interés por producciones españolas innovadoras se explica por las nuevas tendencias que valoran una historieta 0 una novela gráfica donde se privilegia el relato singular, no integrado en una serie así como la calidad literaria.

Gracias a la labor de redes culturales y artísticas transnacionales, los lectores franceses pudieron leer casi al mismo tiempo que los lectores españoles L'expiation de Ricard Castells y Felipe Hernández Cava (1998, de Ponent; 2000, FRM K) o El Hepatmeron de M aría Colino (De Ponent, 1999; L'heptameron, CNBDI, 2001). Otra relevante aventura editorial, representativa de este sector alternativo fue la publicación de Cahier perplexe, cuaderno perplejo, perplexed notebook (FRMK, 2002) en tres idiomas, recopilación de las ilustraciones de prensa de Raúl, entre 1986 y 2002. En esta obra nos damos cuenta hasta qué punto Raúl usa todos los recursos del dibujo contemporáneo, del collage 0 , incluso, 
de la escultura para crear asociaciones entre verbo e imagen pocas veces igualadas. Todo está en la imagen, una imagen, a menudo impenetrable sin la ayuda de esta chispa que es la palabra.

En el paisaje editorial franco-belga recompuesto, menos rígido y hasta deseoso de recuperar lo que procede de publicaciones independientes, la producción española se halla en posición favorable. La prensa franco-belga saluda con artículos elogiosos la presencia renovada de autores y la vitalidad de la producción hispana16.

La atracción por el mercado franco-belga y su política particular de "series" se confirma en personalidades que se integraron hace tiempo en él. Tal es el caso de Ana Miralles, que ya desde la trilogía Eva Medusa con guión de Antonio Segura en los años noventa, tiene su fieles lectores que

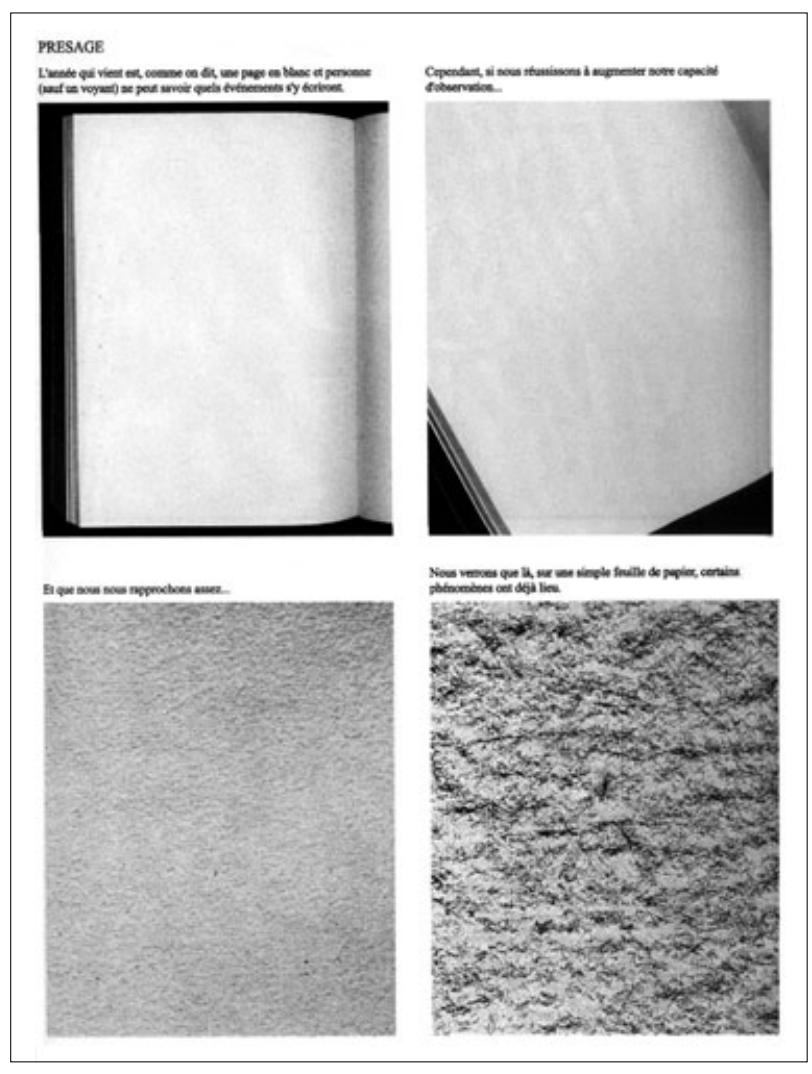

Imagen 7. Sylvestre (Federico del Barrio), "Présage", Beaux Arts Magazine, Hors-série dedicado a la bande dessinée con el tema del año nuevo, diciembre de 2003. siguen siendo seducidos por su interpretación gráfica de la serie Djin con guión de Jean Dufaux en Dargaud. En cuanto a José Luis M unuera, autor prolífico, está completamente integrado en el panorama franco-belga, a través de sus colaboraciones con Joann Sfar o Jean-Louis Morvan, sea en su creación delirante en torno a la figura del mago Merlín (serie publicada en Dargaud entre 1999 y 2003), sea al retomar la serie emblemática Spirou et Fantasio (Dupuis, 2004-2008). En los últimos años, la salida de Blaksad de Juanjo Guarnido y Juan Díaz Canales ha constituido todo un evento. Juanjo Guarnido ganó el premio del mejor dibujo en el Festival de Angulema de 2004. Colaboró con Forum de Planeta DeAgostini, trabajó durante años como dibujante de animación en Madrid y en París (estudios Disney), antes de asomarse a una línea franco-belga que podríamos situar entre Bilal y Sokal. El tomo 4 de Blaksad, L'enfer, le silence prepublicado en el portal del periódico L'Express, acaba de aparecer impreso en la editorial Dargaud. Muy al gusto del lector francés, esta serie supone la consagración de un autor afincado en Francia, adepto de la historieta europea y ahora uno de los más reconocidos y mediatizados en Francia. La ola de la novela gráfica permite a España relacionarse con el resto del mundo y seducir fuera por su narrativa gráfica diversificada (Plein les yeux de Keko, ed. de I'An 2, 2006; Les serpents aveugles de Bartolomé Seguí-Felipe Hernández Cava, Dargaud, col. Long courrier, 2008; Rides o Les rues de sable de Paco Roca, col. Mirages, Delcourt, 2007 y 2009; L'ange de la retirada de Serguei Dounovetz y Paco Roca, col. Plantigrade, 6 pieds sous terre, 2010; El arte de volarde Antonio Altarriba-Kim, Denoël, 2011; Jaime Martín, Ce que le vent emporte, Dupuis, 2007...). El fortalecimiento, aunque siempre relativo, de las editoriales españolas, la normalización del juego de coproducciones, compra y venta de derechos, supone una mejora en la difusión internacional de obras españolas de autores pertenecientes a generaciones diferentes. Por si fuera poco, en el último Festival de Angulema (2010), el Musée de la Cité Internationale de la Bande Dessinée expuso originales de los 100 más destacados autores del mundo que interpretaron una selección de las mejores obras que este museo posee. Entre ellos figuraban los españoles Federico del Barrio, Laura, Max, Mauro Entrialgo, Miguel Ángel Martín, Ana Miralles, Rubén Pellejero, Paco Roca y Miguelanxo Prado17.

La presencia efectiva y numerosa de los historietistas españoles en el tablero internacional no deja lugar a dudas. A lo largo del siglo XX y, sobre todo, a partir de los años cuarenta, la historieta española mostró gran dinamismo fuera 
de sus fronteras, adaptándose o mostrando su disconformidad. Las aportaciones a la historieta mundial son tan heterogéneas que el calificativo de escuela española parece inadecuado. Entre un cómic español que se amoldó a un formato extranjero o lo reinterpretó, participando en su evolución y transformación, y las propuestas singulares -clásicas o más experimentales- que contribuyeron a la reconversión de un producto de consumo en un objeto de arte, los puntos comunes parecen escasos. Sin embargo, siempre se mantuvo la paradoja de la historieta hispana: una efervescencia cultural, social y artística nunca contradicha que corre pareja con un déficit simbólico que impide su total reconocimiento en el ámbito internacional. Acaso herencia del pasado, solo se alcanzará un legítimo reconocimiento fuera de las fronteras cuando se tome en cuenta esa aportación internacional que aquí he intentado calibrar y cuando la historieta adquiera, dentro del país, una legitimidad cultural que se concrete, más allá de premios nacionales, en una política cultural transautonómica a la altura de los hechos.

\section{NOTAS}

1 Véase Alain Beyrand, "Héros quotidiens des années 50 et 60 ", en el portal de Pressibus, http://www. pressibus.org. Pressibus es una asociación, una editorial y una revista especializada en historieta de los años cincuenta a los ochenta en Francia. En 1998, publicó Chéri-Bibi voit rouge, de Regino Bernad y Gaston Leroux, Les albums Pressibus.

2 La revista Période Rouge (20082010), dedicada al estudio de Vaillant y Pif Gadget, presenta en el $n^{\circ} 5$, de septiembre de 2008, y el $n^{\circ} 18$, de octubre de 2009, dos estudios sobre Cabrero Arnal realizados respectivamente por Christian Potus y Hervé Cultru. En el $n^{\circ} 18$ se añade un texto sobre el horror de los campos, "J osé Cabrero Arnal, 39-45 dans I'horreur des camps" (Richard Medioni, Françoise Bosquet).

3 Julio Ribera, Montserrat, ed. Bamboo: t. 1, Souvenirs de la guerre civile, 2004; t. 2, Une jeunesse bafouée, une dictature au fil des jours, 2005; Paris liberté, le parfum de l'espoir, 2006.

4 Otro autor de origen español, Tito (Tiburcio de la Llave), llegó de niño a Francia, dedicó unos relatos gráficos

Recibido: 22 de septiembre de 2010 Aceptado: 30 de noviembre de 2010 a la guerra civil en su serie Soledad: "La mémoire blessée", "L'homme fantôme", Casterman, 1998. En un libro recopilatorio de relatos sobre la guerra civil con guiones de Víctor Mora, Tormenta sobre España (Glénat, 2008) aparecen tres grandes nombres del exilio en historieta: Antonio Parras, Víctor Mora y Florenci Clavé.

5 En 1974 fue premiado en el primer Festival International de la Bande Dessinée de Angoulême. En 1980 le otorgaron el prestigioso premio Yellow Kid.

6 Jesús Blasco fue homenajeado en Francia con exposiciones en la Biblioteca Nacional de Francia y en Angulema, y premiado con el Yellouw Kid en 1982. Planeta-DeAgostini acaba de reeditar para el mercado español The steel Claw, bajo el título Zarpa de acero.

7 En 1974 fue premiado con el Yellow Kid.

8 En España, la editorial Ikusager, cuya política editorial se basa en una concepción del álbum cartoné franco-belga de calidad tanto en la impresión como en la fabricación, con un formato vertical bastante grande, supo acoger en España como se debía la obra de este autor.

9 Cartelista cenetista, que tuvo que exiliarse durante la guerra civil.

10 Hugo Pratt empezó a trabajar con Fleetway en 1959 produciendo sus 
famosos cuadernillos de aventuras bélicas.

11 En el informe anual sobre la bande dessinée Gilles Ratier presenta una lista de 50 álbumes seleccionados por los miembros de la Asociación de Críticos de Bande Dessinée (ACBD). Colocaron en tercer lugar Paracuellos, reeditado por Fluide Glacial-Audie, que recibió el premio del Patrimonio en el festival de Angulema 2010.

\section{BIBLIOGRAFÍA}

AzPITARTE, Koldo (2006): Cómics made in Spain. Dolmen.

Calvo Serraller, Francisco (1990): Del futuro al pasado, Vanguardia y tradición en el arte contemporáneo. Madrid: Alianza Editorial.

CuAdRADO, Jesús (2000): De la historieta y su uso, 1873-2000. Ediciones Sins
12 Entrevista de Claude Duée a Thierry Van Hasselt, no publicada.

13 FREON fusionó después con AM OK Ilegando a ser FRMK (o Frémok) en 2002.

14 La nueva historieta española-La nouvelle bande dessinée espagnole, exposición y catálogo en el XVI Festival de Angulema, comisario Antonio Altarriba, 1989.

15 En rigor, estas redes empezaron en los años setenta cuando, por ejemplo,

Entido- Fundación Germán Sánchez Rupérez.

Fernández, Fernando (2004): Memorias Ilustradas. Glénat.

Martín, Antonio (2006): "Ángel Puigmiquel, patrimonio de la historieta universal", en El ladrón de pesadillas y otras historias. Col. Patrimonio de la Historieta, Glénat, 5-8.
Alt Spiegelman invitaba en su revista Raw a Mariscal y a Martí.

16 En su informe de 2009 sobre el estado de la bande dessinée francobelga, Gilles Ratier nos proporciona dos datos: en 2008 se tradujeron 28 relatos españoles y 20 en 2009.

17 Cent pour Cent Bande Dessinée, catálogo de la exposición, CIBDI, Paris bibliothèques, 2010.

MEDIONI, Richard (ed.) (2008-2009): Période Rouge, $n^{\circ} 5$, septiembre de 2008, y n० 18, octubre de 2009.

PoRTAL PRESSIBUS: http://www.pressibus. org

SorNí, Vicente (2007): "La vuelta del exilio: el renovado éxito de las revistas de género", en La historia del tebeo valenciano. Ediciones de Ponent, 207-233. 